\title{
Obtaining Specific Hybridomas for Ki-67 Protein Immunodetection
}

\author{
Aigerim Turgimbayeva, Sailau Abeldenov, Nurgul Sarina, Bekbolat Khassenov, \\ Saule Eskendirova*
}

National Center for Biotechnology, Kurgalzhynskoye Road, Nur-Sultan, Kazakhstan

*Corresponding author. E-mail: eskendirova@biocenter.kz

Received date: Feb 22, 2021; Revised date: May 27, 2021; Accepted date: May 31, 2021

\section{Abstract}

$\mathrm{B}$

ACKGROUND: Active proliferation is specific property of a tumor cells. However, the cost of the analysis is high due to commercial anti-Ki-67 mAbs used as the main immunoreagent for reliable identification of proliferating cells. In this study, recombinant protein was used to obtain specific mAbs for Ki-67 biomarker immunodetection.

METHODS: Codon optimized fragment of ki-67 gene was cloned into the pET28c(+)vector. The recombinant protein was purified by immobilized metal affinity chromatography (IMAC) and confirmed by liquid chromatography-mass spectrometry (LC-MS)/MS. Hybridoma cells were obtained by fusing myeloma cells with mouse spleen cells immunized with recombinant antigen. The specificity and activity of mAbs was determined by enzymelinked immunosorbent assay (ELISA), Western blot and immunocytochemistry.
RESULTS: The pET-28c $(+) / k i-67$ plasmid, which encodes 355 amino acid protein, was obtained. Analysis by LCMS/MS of the recombinant antigen showed that $77.5 \%$ of the amino-acid sequence belonged to Ki-67 protein. Recombinant fragment of $\mathrm{Ki}-67$ protein was used to obtain specific hybridoma strains. ELISA and Western blot demonstrated high affinity and the specificity of obtained mAbs against Ki-67 protein. Newly generated anti-Ki67 mAbs detected target protein in proliferating cells of MCF7 cell line by immunocytochemistry.

CONCLUSION: Newly developed mAbs are potentially useful as an immunodiagnostic tool for assessing the proliferative activity of breast tumor cells using immunocytochemistry.

KEYWORDS: breast cancer, Ki-67, monoclonal antibodies, nuclear antigen, recombinant antigen, tumor cells

Indones Biomed J. 2021; 13(3): 261-70

\section{Introduction}

Breast cancer is a leading malignant disease among women in many countries, despite its pathology is visually localised. High heterogeneity of breast cancer determines the study of pathological changes at the molecular level.(1-3) Every year in the world over two million women are diagnosed with breast cancer. In 2020 in Kazakhstan breast cancer ranks the first place in the total number of detected cases of cancer patients to $37.1 \%$ of all 35366 registered cases.(4)

Early diagnosis of breast cancer determines the clinical course and prognosis of the disease.To confirm the pathology of the mammary glands using cytomorphological diagnostics by fine needle aspiration cytology (FNAC). However, the reliability and accuracy of the cytological study varying from 34 to $65 \%$.(5) In the recent years, FNAC technique is improved by the development immunocytochemistry (ICC) based to determine the molecular biomarkers of tumors. Immunocytochemical characterization of breast carcinoma on fine-needle aspirates (FNA) is recognized as an effective method study the prognostic and predictive molecular biomarker of tumor cells for early diagnosing of malignancy. Assessment of status in lymph nodes from patients receiving neoadjuvant therapy or patients with inoperable metastases in FNA 
samples using ICC has been successful to predict the course of the treatment.(6-9)

As known active proliferation is specific property of a tumor cells population. At present, detection of cell proliferation index using the Ki-67 biomarker is widely used as potential prognostic biomarker in breast carcinoma in diagnostic routine clinical practice. The Ki-67 biomarker is mainly associated with chromosomes and belongs to the family of perichromonucleic proteins that surround chromosomes during mitosis.(10) The Ki-67 nuclear antigen is present in the G1, S, G2, and mitotic phases of the cell cycle, but is not present in G0. Starting from the middle of the G1 phase, Ki-67 expression gradually increases, reaches a peak in metaphase during mitosis, and decreases during anaphase. The Ki-67 antigen is a regulatory cell-cycle protein that is vital in mitosis.(11-13) Thus, the presence of Ki-67 in nearly all phases of the mitotic cycle, and its disappearance upon transition into the resting period, renders it an optimal marker for assessing cellular proliferation.

The immunocytochemistry in FNA samples with biomarkers Ki67 showed it is possible to differentiate in the identification of benign and malignant lesions. Determination of Ki67 biomarker on FNA samples by immunocytochemistry is recommended for the screening and early diagnosis of breast cancer.(5,14) After the discovery of the Ki-67 full structure and the construction of its domains and subdomains using methods of genetic engineering, it became possible to obtain monoclonal antibodies $(\mathrm{mAbs})$ with an epitope-specific orientation. (15) However, the cost of the analysis of is very high due to used commercial anti-Ki-67 mAbs as the main immunoreagent for reliable identification of proliferating cells. In this study, recombinant fragment of Ki-67 protein was used to obtain specific mAbs that allow to reliably identify the Ki-67 biomarker. Obtained specific mAbs can be used to evaluate the proliferative activity of tumor cells using immunocytochemistry (ICC) in FNA samples for the screening and early breast cancer diagnostics.

\section{Methods}

Cloning and Expression of the $\mathbf{k i - 6 7}$ Gene Fragment in Escherichia coli and Purification of Recombinant Ki-67 Protein

Gene sequence of human ki-67 was derived from the National Center for Biotechnology Information (NCBI) Genbank (NM 001145966.2) and used to engineer a synthetic gene encoding protein fragment (amino acid region at 1160-1493). To optimize the expression of recombinant eukaryotic Ki-67 protein in prokaryotic $E$. coli cells, the codon optimization of target gene fragment was performed through a table of $E$. coli frequently used codons. (16) The optimized sequence was verified by GenScript online service (https://www.genscript.com/tools/rarecodon-analysis). A resulting 1002 bp gene sequence was synthesized and provided as pTopBluntV2/ki-67 plasmid by Macrogen (Seoul, South Korea).

The fragment of ki-67 gene was cloned into the pET28c $(+)$ expression vector with primers NdeI-fw-Ki67 (5'-GGGAATTCCATATGTTCCTGGCGCTGAGGAA AC-3') and BamHI-rv-Ki67 (5'-CGCGGATCCTTACG CGATTTTGGTTGTTTTTTC-3'). The plasmid insert was sequenced using BigDye Terminator v. 3.1 Cycle Sequencing Kit (Applied Biosystems, Foster City, CA, USA) on an ABI 3730xl sequencer (Applied Biosystems, Foster City, CA, USA).

A single colony of recombinant $E$. coli strain BL$21(\mathrm{DE} 3) / \mathrm{pET} 28 \mathrm{c}(+) / k i-67$ was incubated in 1L LB broth with kanamycin $(50 \mu \mathrm{g} / \mathrm{mL})$ (Sigma-Aldrich, Taufkirchen, Germany) at $37^{\circ} \mathrm{C}, 200 \mathrm{rpm}$ upon reaching $\mathrm{OD}_{600}=0.6$. The culture was induced by $1 \mathrm{mM}$ isopropyl- $\beta$-D-1thiogalactopyranoside (IPTG; AppliChem Lifescience, Darmstadt, Germany) at $37^{\circ} \mathrm{C}, 200 \mathrm{rpm}$ for 2 hours. The precipitate was resuspended in $10 \mathrm{~mL} 1 \%$ Triton X-100, $20 \mathrm{mM} \mathrm{NaCl}$, and $20 \mathrm{mM}$ Hepes-KOH $\mathrm{pH}$ 7.5, shaken (100 rpm, $22^{\circ} \mathrm{C}, 30$ minutes) and centrifuged $(18000 \times \mathrm{g}$, $4^{\circ} \mathrm{C}, 30$ minutes). The pellet was resuspended in $10 \mathrm{~mL}$ $1 \mathrm{M}$ urea, $20 \mathrm{mM}$ HEPES-KOH $\mathrm{pH} 7.5$, and $10 \mathrm{mM}$ betamercaptoethanol. This procedure was repeated using $3 \mathrm{M}, 5$ $\mathrm{M}$, and $8 \mathrm{M}$ urea. Supernatants were collected and pooled. The recombinant protein was purified by immobilized metal affinity chromatography (IMAC) using $2 \mathrm{~mL}$ Ni-NTA agarose (Qiagen, Germantown, MD, USA). The desired fractions were combined and dialyzed against phosphate buffered saline (PBS) for 24 hours. Samples were stored in $50 \%$ glycerol at $-20^{\circ} \mathrm{C}$.

\section{Liquid Chromatography Combined with Mass Spectrometry (LC-MS/MS)}

Proteins were separated by sodium dodecyl sulphatepolyacrylamide gel electrophoresis (SDS-PAGE) using $4-12 \%$ gradient polyacrylamide gels. Candidate bands were excised from the gels, alternately treated with $50 \mathrm{mM}$ ammonium bicarbonate and 100\% acetonitrile. Activated by $190 \mathrm{mM}$ ammonium bicarbonate trypsin (Promega, Madison, WI, USA) was added to the samples. The peptide mixture was purified by ZipTipC18 (Millipore, Darmstadt, 
Germany) and dried in a vacuum concentrator $\left(35^{\circ} \mathrm{C}, 30\right.$ minutes). The precipitate was suspended in $10 \mu \mathrm{L} 0.1 \%$ trifluoroacetic acid for mass spectrometry analysis.

The peptides were separated by high performance liquid chromatographic using an Acclaim PepMap100 C18 capture column ( $5 \mathrm{~mm}$ x $300 \mu \mathrm{m}$; particles $5-\mu \mathrm{m}$ in diameter; Thermo Scientific, Austin, TX, USA) and Dionexpump (Thermo Scientific, Austin, TX, USA). Peptides were further separated on an Acclaim PepMap RSLC column (15 $\mathrm{cm} \times 75 \mu \mathrm{m}$, particles $2-\mu \mathrm{m}$ in diameter; Thermo Scientific, Austin, TX, USA). An unmodified Captive Spray ion source (capillary voltage of $1300 \mathrm{~V}$, dry gas flow of $3 \mathrm{~L} /$ min, and dry temperature of $150^{\circ} \mathrm{C}$ ) was used to interface the liquid chromatography (LC) system with Impact II. Mascot software was used to search the Swiss Prot 2014_08 database (546238 amino acid sequences; 194363168 amino acid residues). Search parameters were set as follows: modification variables, oxidation $(\mathrm{M})$; fragment ion mass tolerance, 20 ppm; parent ion tolerance, $20 \mathrm{ppm}$.

\section{Production of mAbs Against Ki-67 Protein}

Studies were conducted on 6 BALB/c mice (The Jackson Laboratory, Bar Harbor, ME, USA), 6-8 weeks old females, weighing 20-25 g. Animals were obtained from the Animal facility of the National Center for Biotechnology (NCB), Nur-Sultan city, Kazakhstan. All procedures involving animals were conducted in accordance with the guidelines of NCB and approved by Institutional Animal Care and Use Committee (protocol \#2 June 2, 2020). Animals were housed in special facility with 12-hour light dark cycle. They were fed by standard mouse chow, water and food provided ad libitum.

On the first day of immunization, BALB/c mice (6-8 weeks old) were intraperitoneally injected with $0.05 \mathrm{mg}$ recombinant Ki-67 protein emulsified in $0.1 \mathrm{~mL}$ of Freund's complete adjuvant. On days 7, 11, 12, 13 of immunization, were injected with $0.025 \mathrm{mg}$ of antigen in. of PBS pH 7.2. Hybridization of myeloma cells X63Ag8.653 (ATCC, Manassas, VA, USA) with spleen cells from immunized mice was performed according to the method of Oi and Herzenberg.(17) The fusion agent was used $45 \%$ solution of polyethylene glycol-4000 (PEG; Merck, Darmstadt, Germany) and as selective HAT (hypoxanthine, aminopterin, and thymidine) medium (Sigma-Aldrich, Saint Louis, MO, USA). The productivity of the hybrid cells determine by indirect enzyme-linked immunosorbent assay (ELISA) using recombinant protein Ki-67.

Single-cell cloning of hybrid cells was carried out using the limiting dilution method.(18) The concentration of
mAbs in ascitic fluid was determined using Bradford assay. (19) Isotypes of mAbs were determined using a IsoStrip ${ }^{\text {TM }}$ Mouse Monoclonal Antibody Isotyping Kit (SigmaAldrich,Taufkirchen, Germany).

\section{Indirect ELISA}

Indirect ELISA was performed by coating a 96-well plate with recombinant antigen Ki-67 at a concentration of 0.001 $\mathrm{mg} / \mathrm{mL}$ in $0.1 \mathrm{~mL}$ of PBS ( $\mathrm{pH} 7.2$ ) and incubated overnight at $4{ }^{\circ} \mathrm{C}$. Primary antibody (blood sera of immunized mice, supernatant or ascitic fluid mAbs) was added to the wells and incubated for $1 \mathrm{~h}$ at $37^{\circ} \mathrm{C}$. Further, rabbit anti-mouse secondary antibody (labeled with horseradish peroxidase) diluted 1:5000 in PBST. After of incubation a substrate 3,3',5,5'-tetramethylbenzidine (Sigma-Aldrich, Taufkirchen, Germany) was added. The absorbance of the final product was measured at $492 \mathrm{~nm}$, using a spectrophotometer.

\section{Western Blot}

Western blot of recombinant Ki-67 protein was performed by standard method.(20) Obtained 4B8 mAbs were used as the primary antibodies at 1:500 dilution, $4^{\circ} \mathrm{C}$ overnight. Commercial anti-Ki67 mAbs B56 (550609, BD Pharmingen, San Jose, CA, USA) were used as positive control at 1:250 dilution. Goat anti-mouse antibodies conjugated with horseradish peroxidase (Sigma-Aldrich) were used as the secondary antibodies at 1:10000 dilution. The developing buffer includes the substrate solution, which contains 0.48 $\mathrm{mM}$ 4-Chloro-1-Naphthol (Sigma-Aldrich), $50 \mathrm{mM}$ Tris$\mathrm{HCl}$ and $0.2 \mathrm{M} \mathrm{NaCl}$ in $17 \%$ methanol, and $0.01 \mathrm{~mL}$ of $3 \%$ $(\mathrm{v} / \mathrm{v})$ hydrogen peroxide.

\section{ICC}

Breast adenocarcinoma cells MCF-7 (ATCC, Manassas, VA, USA) were passaged on culture slides at a density of 50000 cells/well until a monolayer was formed with a confluence index of $80 \%$. After reaching the required level of confluence, cells fixed with $4 \%$ paraformaldehyde for $20 \mathrm{~min}$ at $37^{\circ} \mathrm{C}$. After removing $4 \%$ paraformaldehyde, to permeabilize the cell membranes, cells were treated with $0.3 \%$ Triton X-100 for $20 \mathrm{~min}$. After block nonspecific binding 1\% BSA, the cells were incubated with primary antibodies, 4B8 mAbs, at dilutions of 1:50 - 1:100. Commercial B56 mAbs at 1:50 dilution was used as positive control. Subsequently, a secondary conjugated antibody, anti-mouse Alexa Fluor 488 (Abcam, Burlingame, CA, USA), was added at 1:500 dilution. Images were captured at $40 \mathrm{X}$ magnification in a fluorescent microscope (Axio Observer, Carl Zeiss, Heidelberg, Germany) using a green filter. 


\section{Results}

\section{Expression and Purification of Recombinant KI-67 Protein}

Part of the central domain Ki-67 protein with 16 repeating elements (i.e., "Ki-67 repeats" (amino acid region at 11601493) was selected as antigen to obtain mAbs. This protein fragment is encoded by 1002 bp (NM_001145966.2, region: 2812-5640). To optimize the expression of recombinant eukaryotic Ki-67 protein in prokaryotic E. coli cells, the codon optimization of ki-67 gene was performed through a table of frequently used E. coli codons. The Codon Adaptation Index (CAI) of the obtained gene sequence was 0.82 relative to the optimal range $(0.8-1.0)$. GC content of the gene was $53.71 \%$, which fell within the required 30 $70 \%$ range. The percentage of low-frequency codons, which should not exceed $30 \%$, was $3 \%$. The initial sequence of $k i-67$ gene fragment, selected for the codon optimization, is shown in Supplementary 1.

The synthesized gene encoding the recombinant protein, which is identical to the reference protein, was cloned into a pET-28c(+) vector at the NdeI and BamHI sites. Amplified gene is presented in Supplementary 2. Genetic map of the resulting plasmid pET28c $(+) / \mathrm{ki}-67$ is shown in Figure 1 . The $k i-67$ gene is controlled by the $\mathrm{T} 7$ promoter in $\mathrm{pET} 28 \mathrm{c}(+) / k i-67$ plasmid, the resulting recombinant fragment of Ki-67 protein carries an N-terminal 6xHis-tag. The open reading frame of the vector encodes a recombinant protein that contains 355 amino acid residues and has an estimated molecular weight of $38.5 \mathrm{kDa}$.



Figure 1. Genetic map of pET28c(+)/ki-67 plasmid. The $k i-67$ gene is controlled by the $\mathrm{T} 7$ promoter, the recombinant fragment of Ki-67 protein carries an N-terminal 6xHis-tag, the length of the open reading frame is $1068 \mathrm{bp}$.
Induction of protein expression for 16 hours did not lead to a significant increase in the amount of recombinant protein. SDS-PAGE showed protein accumulation at 45 $\mathrm{kDa}$, which was $\sim 6.5 \mathrm{kDa}$ greater than the calculated mass of Ki-67 (Figure 2). Proteins with high proline content show reduced electrophoretic mobility because of bending and structural rigidity of the primary sequence. This can lead to an error of $\pm 10 \%$ in SDS-PAGE to determine the molecular weight of the protein. There are 32 proline residues in the structure of obtained recombinant Ki-67 protein, which may explain the observed mismatch in molecular weight obtained by electrophoresis. To verify our assumption, we analyzed the $45-\mathrm{kDa}$ candidate protein by LC-MS/MS. We obtained a score of 10304 for peptides identified in the isolated protein, indicating that they belonged to Ki-67. Results of LC-MS/MS for identification of Ki-67 are presented in Supplementary 3. Analysis using Mascot program found peptides related to trypsin, keratin, and numerous other proteins. The presence of trypsin in the sample was likely due to porcine trypsin used in sample preparation. The presence of keratin peptides likely resulted from slight contamination during the experiment. The presence of other proteins may have been a coincidence in the $\mathrm{m} / \mathrm{z}$ of primary and secondary ions, as confirmed by the low score. Analysis conducted by overlapping the identified peptides of the recombinant $\mathrm{Ki}-67$ fragment showed that $77.5 \%$ of the amino-acid sequence belonged to Ki-67 protein (Figure $3)$. Cloned protein fragment is framed; identified peptides are bold. Protein sequence coverage in the recombinant Ki67 protein fragment: $77.5 \%$.

After verification of Ki-67 expression, a culture of the recombinant $E$. coli $\mathrm{BL}-21$ (DE3)/pET28c $(+) / k i 67$ strain was developed for purification by IMAC (Figure 4A) The obtained fractions 1 and 2 were combined and used for the second step of purification (Figure 4B). Fractions 4-6 were combined and dialyzed against PBS for 24 hours. After dialysis the total protein yield was $47.22 \mathrm{mg}$ from $1 \mathrm{~L}$ bacterial culture.

\section{Production of the Hybridoma Strains}

To immunize BALB/c mice with the recombinant protein $\mathrm{Ki}$ 67 , the 2-week scheme was used. The optimal combination of five injections of the recombinant $\mathrm{Ki}-67$ protein fragment produced sufficient amount of serum antibodies with a high titer for the antigen -1:102400-1:204800 (Figure 5). Specificity of interaction the recombinant Ki-67 antigen was confirmed using anti-Ki-67 mAbs named B56 as positive control and anti-human c-ErbB-2 $\mathrm{mAbs}$ as negative control (554299, BD Pharmingen). Our results indicate that 


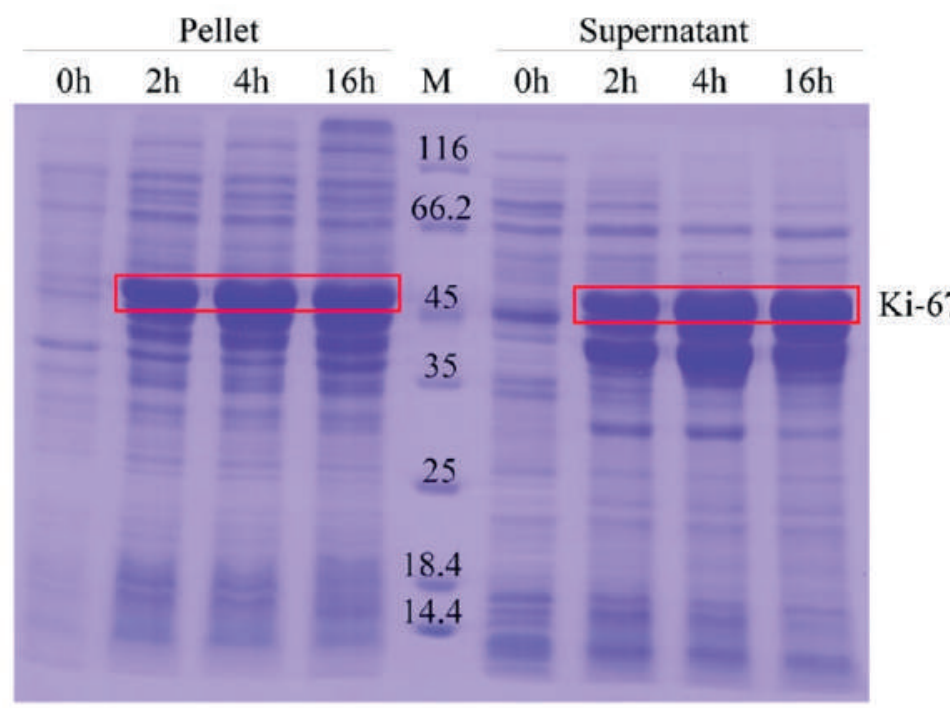

Figure 2. Analysis of Ki-67 expression level in $E$. coli BL-21 (DE3)/pET28c(+)/ki-67 cells. M: protein ladder (26610, Thermo scientific); 0h: no induction by IPTG; 2h: 2 hours of incubation after induction; $4 \mathrm{~h}: 4$ hours of incubation after induction; 16h: 16 hours of incubation after induction.

recombinant $\mathrm{Ki}-67$ protein did not react with anti-human c-ErbB-2 mAbs, but it actively reacted with anti-Ki-67 B56 mAbs. Further, immunized mouse spleen cells were selected for hybridization with X63 myeloma cells.

Out of the total hybridomas seeded in 384 wells, growth of colonies was observed in 187-224 wells, i.e., the percentage of cell fusion was high (48.6-58.3\%).
Furthermore, the yield of positive clones obtained from total number of hybridomas was within $9.8 \%$ to $12.5 \%$, indicating the possibility of isolating active clones with desired properties. Activity of hybridoma clones was examined five times by ELISA in an interval of 3-4 days.

Clones of 4B8, 7D2 and 10F5 cells, as the most active and stable lines of hybridomas, were cloned by the method

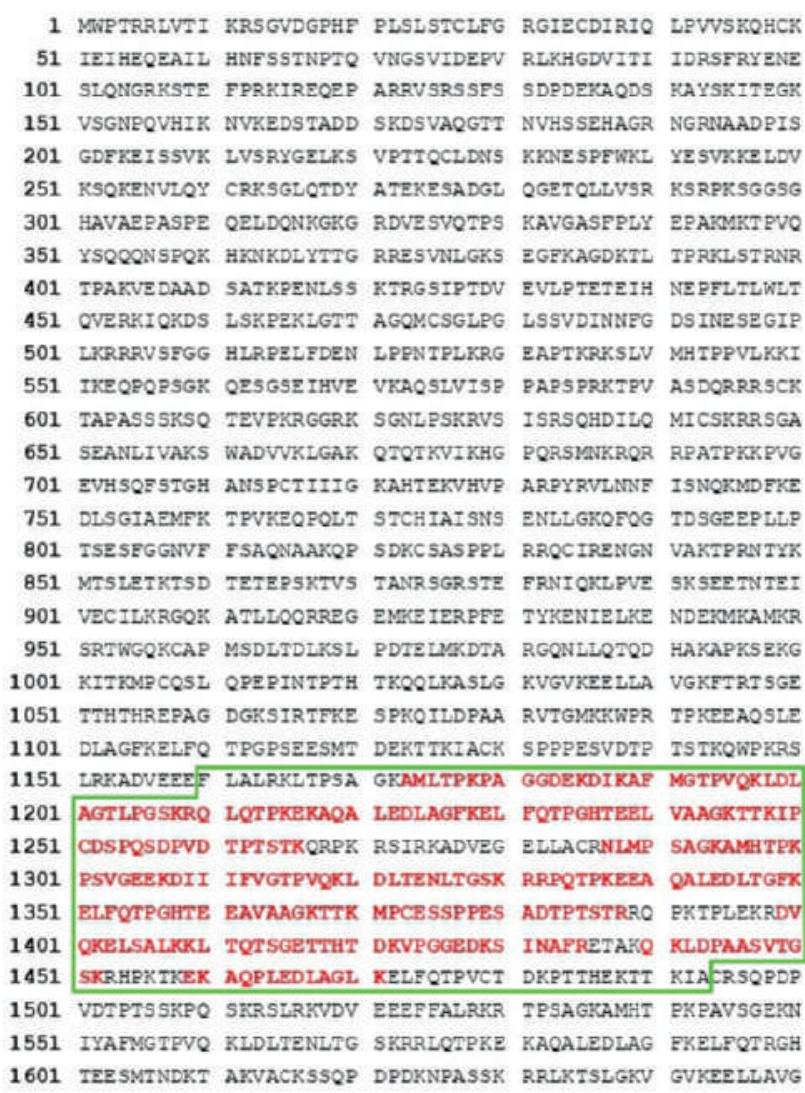

1651 KLTOTSGETT HTHTEPTGDG KSMKAFMESP KOILDSAASL TGSKROLRTP 1701 KGKSEVPEDL AGFIELFQTP SHTKESMTNE KTTKVSYRAS QPDLVDTPTS 1751 SKPOPKRSLR KADTEEEFLA FRKQTPSAGK ANHTPKPAVG EEKDINTFLG 1801 TPVQKLDQRG NLPGSNRRLQ TRKEKAQALE ELTGFRELFO TPCTDNPTTD 1851 IKTTKKILCK SPQSDPADTP INTKQRPKRS LKKADVEEEF LAFRKLTPSA 1901 GKAMHTPKAA VGEEKDINTE VGTPVEKLDL LGNLPGSKRR POTPKEKAKA 1951 LEDLAGEKEL FOTPGHTEES MTDDKITEVS CKSPOPDPVK TPTSSKORLK 2001 ISLGKVGVKE EVLPVGKLTQ ISGKTTQTHR ETAGDGKSIK AFKESAKGML 2051 DPANYGTGNE RWPRTPKEEA QSLEDLAGKK ELFOTPDHTE ESTTDDKTTK 2101 IACKSPPPES MDTPTSTRRR PKTPLGKRDI VEELSALKOL TOTTHTDKVP 2151 GDEDKGINVE RETAKQKLDP AASVTGSKRQ PRTPKGKAQP LEDLAGLKEL 2201 FOTPICTDKP TTHEKTTKIA CRSPOPDEVG TPTIFKPOSK RSLRKADVEE 2251 ESLALRKRIP SVGKAMDIPK PAGGDEKDMK AFMGTPVOKL DLPGNLPGSK 2301 RWPQTPKEKA QALEDLAGEK ELFQTPGTDK PTTDEKTTKI ACKSPQPDPV 2351 DIPASTKQRP KRNLRKADVE EZFLALRKRT PSAGKAMDTP KPAVSDEKII 2401 NTEVETPVOK LDLLGULGS KROPOTPKER AEALEDLVGF KELFOTPGHT 2451 EESMTDDKII EVSCKSPQRE SFKTSRSSKO RLKIPLVKVD VKEERLAVSK 2501 LTRTSGETTO IHTEPTGDSK STKAFKESPK OILDPAASVI GSRRQLRTRK 2551 EKARALEDLV DEKELFSAPG HTEESMTIDK NTKIPCKSPP PELTDTATST 2601 KRCPKTRPRK EVKEZLSAVE RLTQTSGQST HTHKEPASGD EGIKVLKQRA 2651 KKKPNPVEZE PSRRRPRAPK EKAQPLEDLA GFTELSETSG HTQESLTAGK 2701 ATKIPCESPP LEVVDTTAST KRHLRTRVOR VOVKEEPSAV KFTOTSGETT 2751 DADKEPAGED KGIKALKESA KOTPAPAASV TGSRRRPRAP RESAQAIEDL 2801 AGFKDPAAGH TEESMTDDKI TKIPCKSSPE LEDTATSSKR RPRTRAQKVE 2851 VKEELLAVGK LTOTSGETTH TDKEPVGEGK GTKAFKOPAK RKLDAEDVIG 2901 SRRQPRAPKE KAQPLEDLAS FQELSQTPGH TEELANGAAD SFTSARKQTP 2951 DSGKPLKISR RVLRAPKVIR VGDVVSTRDP VKSOSKSNTS LPPLPFKRGG 3001 GKDGSVTGTK RLRCMPAPEE IVEELPASKK ORVAPRARGK SSEPVVIMKR 3051 SLRTSAKRIE PAEELNSNDM KTNKEEHKLO DSVPENKGIS LRSRRONKTE 3101 AEQQITEVFV LAERIEINRN EKKPMKTSPE MDIQNPDDGA RKPIPRDKVT 3151 ENKRCLRSAR ONESSOPKVA EESGGOKSAK VLMONOKGKG EAGNSDSMCL 3201 RSRKTKSOPA ASTLESTSVQ RVIRSVKRCA ENPKKAEDNV CVKKIRTRSH 3251 RDSEDI

Figure 3. Overlap of the recombinant Ki-67 protein fragment with identified peptides by LC-MS/MS. Green frame: fragment of expressed protein; Red bold font: identified peptides. 


\section{A - Solubilization of the recombinant protein Ki- 67 by Triton X-100 and urea}

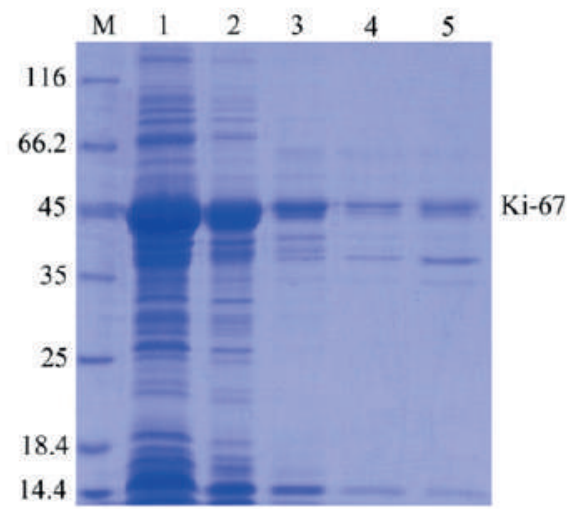

M - marker;

$1-1 \%$ Triton X-100;

2 - $1 \mathrm{M}$ urea;

3 - $3 \mathrm{M}$ urea;

$4-5 \mathrm{M}$ urea;

$5-8 \mathrm{M}$ urea

B - Second step of the recombinant $\mathrm{Ki}-67$ protein purification



M - marker;

1 - load;

2 - flow through;

3 - wash;

4 - $50 \mathrm{mM}$ imidazole fraction;

5 - $100 \mathrm{mM}$ imidazole fraction;

6 - $200 \mathrm{mM}$ imidazole fraction;

7 - 300 mM imidazole fraction;

8 - $400 \mathrm{mM}$ imidazole fraction;

9 - $500 \mathrm{mM}$ imidazole fraction

Figure 4. Purification of the recombinant protein Ki-67 by IMAC.

of limiting dilutions. We found in genetically homogeneous or monoclonal cell population, as $85.9 \%$ to $94.4 \%$ of the subclones synthesized immunoglobulins specific to the recombinant Ki-67 protein fragment.

mAbs from the ascitic fluid were salted out using a saturated solution of ammonium sulfate. Purification of mAbs was performed by affinity chromatography, using

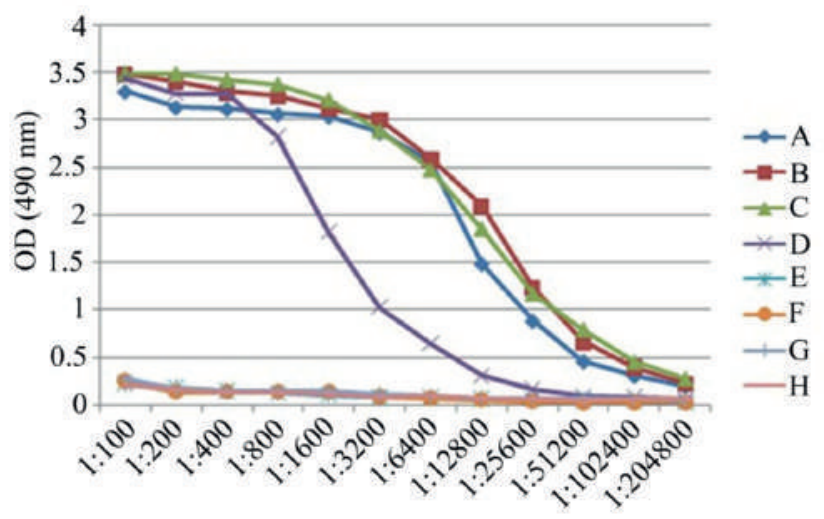

Antibody titer

Figure 5. Antibody titer of sera from immunized mice. A,B,C: sera from immunized mice $(n=3) ; \mathrm{D}$ : commercial anti-Ki-67 mAbs; E: commercial anti-c-erB-2 mAbs; F,G,H: sera from nonimmunized mice $(n=3)$.
MabTrap Kit columns (GE Healthcare Life Sciences, Uppsala, Sweden). The in vivo cultivation of hybridoma cells led to significant increase in the concentration of mAbs to $2-4 \mathrm{mg} / \mathrm{mL}$ in the ascitic fluid, whereas the cultivation under in vitro conditions was $60-125 \mu \mathrm{g} / \mathrm{mL}$. It was found that the hybridoma-synthesized antibodies were related to IgG class, the most active class of immunoglobulins.

\section{The Specificity and Activity anti-Ki-67 mAbs}

The specificity and activity of the hybridoma strains (4B8, $10 \mathrm{~F} 5$, and 7D2) that produced mAbs were determined by indirect ELISA (Table 1). According to the results obtained from indirect ELISA, highest specificity to recombinant Ki-67 antigen showed 4B8 mAbs both in the culture fluid (1:512) and in the ascitic fluid (1:204800). However, the activity another of 7D2 mAbs to recombinant Ki-67 antigen was lower, which amounted to 1:64 in the culture fluid and 1:51200 in the ascitic fluid. The tested mAbs did not interact with extracellular domain of the recombinantc-ErbB-2 (the epidermal growth factor receptor of tumor cells).

The specificity of the isolated mAbs of the hybridoma strains was confirmed using a commercial $\mathrm{mAb}$, antiKi-67 B56, as a positive control. Same levels of titers the experimental $\mathrm{mAbs}$ and commercial $\mathrm{mAbs}$ indicated that 
Table 1. Indirect ELISA to study the specificity and activity of mAbs of 4B8, 10F5, and 7D2 hybridoma strains.

\begin{tabular}{lcccc}
\hline \multicolumn{1}{c}{ Antigen Name } & \multicolumn{4}{c}{ Monoclonal Antibody Titers } \\
\cline { 2 - 5 } & $\mathbf{4 B 8}$ & $\mathbf{7 D 2}$ & $\mathbf{1 0 F 5}$ & mAbB56 \\
\hline Recombinant fragment of Ki-67 protein & $(1: 512) /(1: 204800)$ & $(1: 64) /(1: 51200)$ & $(1: 256) /(1: 102400)$ & $1: 51200$ \\
Recombinant extracellular domain of c-ErbB-2 & No reaction & No reaction & No reaction & No reaction \\
\hline
\end{tabular}

numerator: titers in the culture fluid; denominator: titers in the ascite fluid.

both the antibodies recognized identical epitopes of the recombinant Ki67 antigen.

The specificity of the hybridoma strain 4B8 mAbs and commercial anti-Ki-67 B56 mAbs to the analogous epitope of the recombinant protein Ki-67 was confirmed by western blot (Figure 6). In both cases western blot analysis revealed the presence of a protein with a molecular weight of $45 \mathrm{kDa}$, a recombinant fragment of Ki-67 protein. Among them, 4B8 clones with a titer of 1:204800 in ascitic fluid were selected as suitable for research.

Intense staining of the nuclei of breast adenocarcinoma cells MCF-7 was revealed by ICC analysis using mAbs of 4B8 hybridoma strain (Figure 7). Specificity of detection to Ki-67 protein confirmed identical staining of nuclei of MCF7 cells of commercial B56 mAbs. Intranuclear localization of the detected antigen suggests that 4B8 mAbs specifically interact with the nuclear protein Ki-67- biomarker of cell proliferation.

\section{Discussion}

Detection of cell proliferation is widely used in biomedical routine clinical practice. The main area of Ki-67 antibody application is ICC and immunohistochemical (IHC) methods. In this study, we have successfully produced novel anti-Ki-67 mAbs to detect biomarker of cell proliferation, the $\mathrm{Ki}-67$.
Cell proliferation as a fundamental biological process, as well as a specific property of a transformed cells population that determines of malignancy of disease.(21) Currently, the most informative, accessible and common method of evaluation of the cell proliferative activity level is the identification of the molecilar biomarker, nuclear protein $\mathrm{Ki}-67$. Immunochemically positive reaction to $\mathrm{Ki}-$ 67 shows that the cell is in the interval from the late G1 phase to the M phase inclusive.(11-13) The Ki-67 protein is mainly associated with chromosomes, is detected in the telomere and centromere regions and belongs to the family of perichromonucleic proteins surrounding chromosomes during mitosis. $(10,12)$

The primary transcript of human ki-67 gene is alternatively spliced. Two transcripts with different inclusion of exon 7 encode two $320-\mathrm{kDa}$ and $350-$ $\mathrm{kDa}$ protein isoforms. The nuclear $\mathrm{Ki}-67$ protein has an amphiphilic structure: its C-terminus can bind DNA and its N-terminus has an affinity for the cytoplasm. Although its splice variants differ in their N-terminus, they contain identical C-terminal and central (i.e., Ki-67 domain) regions. Largest $\mathrm{Ki}-67$ domain composed of multiple repetitive elements consisting of 122 amino acids in length with $82-100 \%$ homology, "Ki-67 repeats".(10$12,22,23)$ The targeting to largest "Ki-67 repeats" domain of multiple repetitive elements, which is unique to the Ki67 protein, determines the epitope specificity of the most used commercial $\mathrm{mAb}$ for $\mathrm{Ki}-67$ detection in clinical

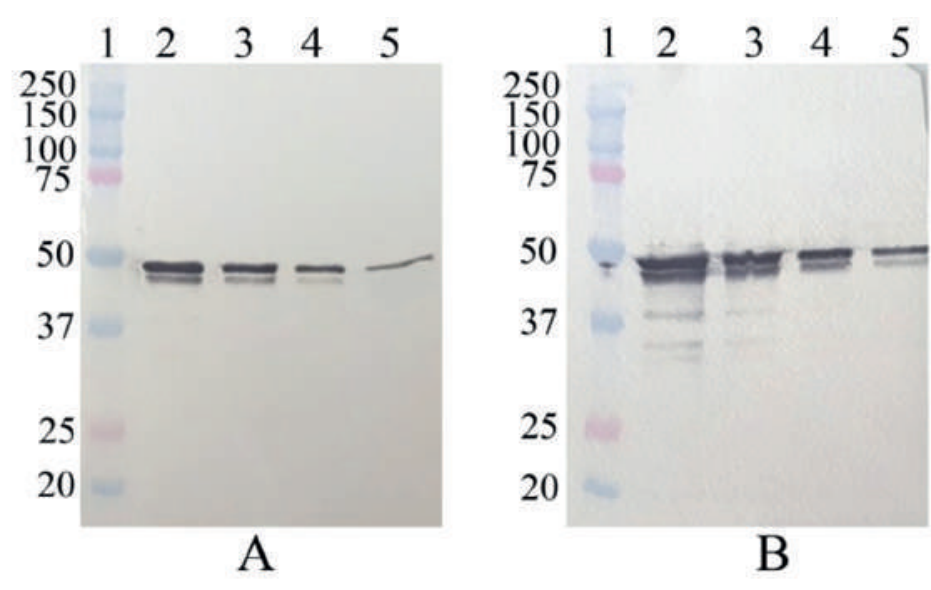

Figure 6. Western blot analysis of the specificity of commercial mAbs (A) and the hybridoma strain 4B8 mAbs (B) to recombinant protein Ki-67. 1: protein ladder; 2: $1 \mu \mathrm{g}$ recombinant antigen (Ki-67); 3: $600 \mathrm{ng}$ recombinant antigen (Ki-67); 4: $300 \mathrm{ng}$ recombinant antigen (Ki-67); 5: 100 ng recombinant antigen (Ki-67). 


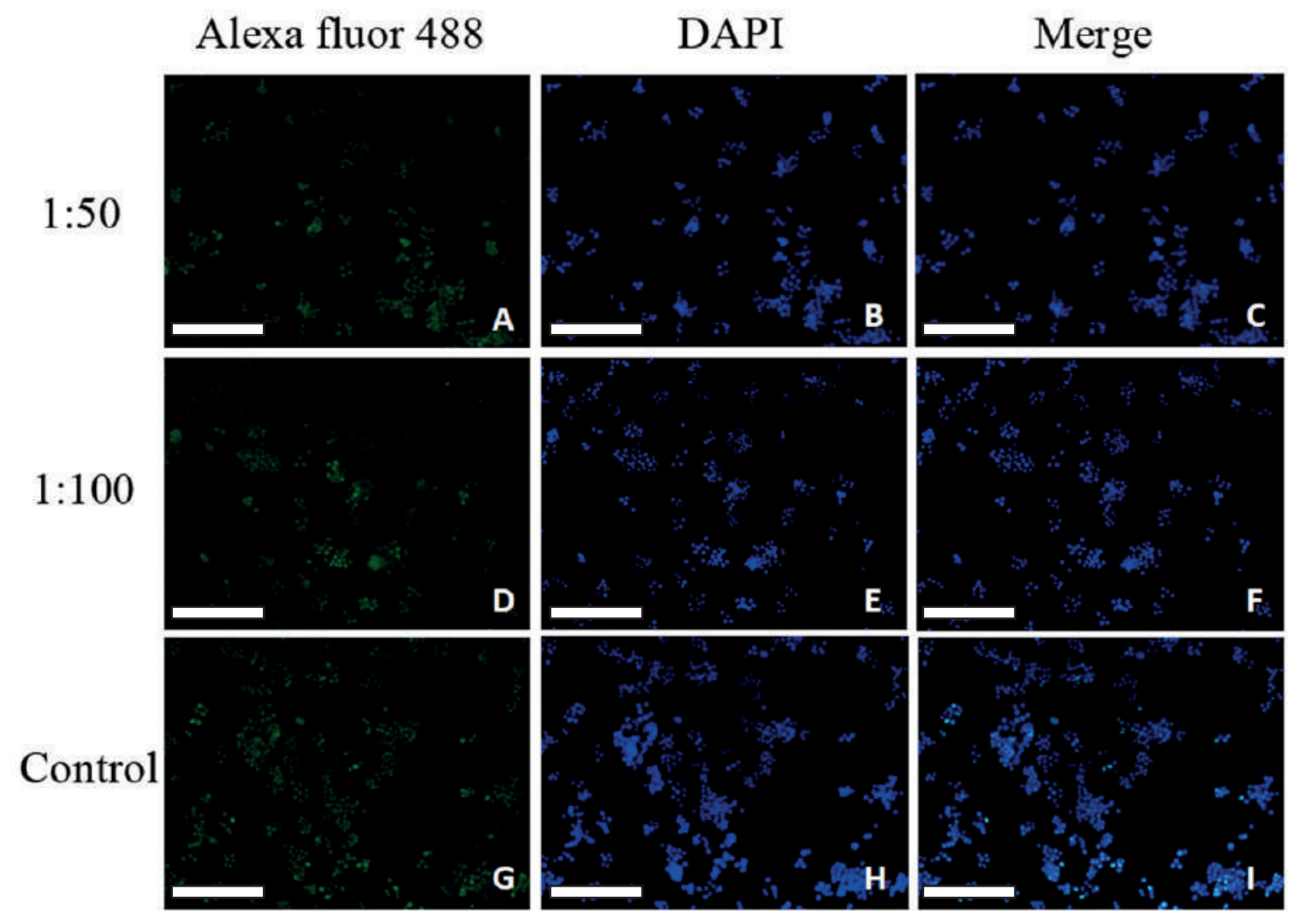

Figure 7. Immunocytochemical analysis of Ki-67 protein expression in breast adenocarcinoma cells MCF-7. A,B,C: 4B8 mAbs at 1:50 dilution; D,E,F: 4B8 mAbs at 1:100 dilution; G,H,I: commercial B56 mAbs at 1:50 dilution. Magnification 40X.

practice, MIB-1, 30-9 and SP6.(15,24-28) The synthesized ki-67 gene fragment of recombinant $\mathrm{Ki}-67$ protein with a length of 1002 bp (334 amino acids, region 1160-1493 aa) was used for production of specific anti-Ki-67 mAbs.The absence or low level of expression of heterologous protein is often observed in E. coli cells. In order to increase the expression level in E. coli, the nucleotide sequence of the human ki-67 gene was changed so that E. coli could easily recognize this sequence while maintaining the same amino acid sequence of the protein. The nucleotide sequence of the ki-67 gene has been optimized taking into account the relative codon frequency, GC content, the presence of hairpins and negative cis-regulatory elements that affect the expression level of a heterologous protein.(29) The codon optimized gene was synthesized and cloned into the vector pET-28c (+) for expression in E. coli BL-21 (DE3) cells. The yield of the recombinant protein was $47.22 \mathrm{mg} / \mathrm{L}$ due to the optimized induction parameters. It should be noted that the structural rigidity of the primary sequence reduced the electrophoretic mobility of the Ki-67 protein because of the high proline content.(30) As a result, SDS-PAGE showed a recombinant protein with a higher molecular weight than expected. The resulting protein was confirmed by LC-MS/
MS, $77.5 \%$ of the amino-acid sequence in the recombinant protein belonged to Ki-67.

Successful generation of hybridomas to produce $\mathrm{mAbs}$ is determined by the nature of immunogen and the efficiency of immunization in mice, which are the donors of immune B-lymphocytes that are hybridized with myeloma cells. The two-week scheme of immunization of BALB/c mice with the recombinant fragment of $\mathrm{Ki}-67$ protein was suitable for stimulating the immune system of the organism. All immunized mice produced strong immune response with antisera titers above 1:102400, that considered as active B-lymphocyte clones producing specific antibodies in the spleens of immunized mice. These results suggested that recombinant $\mathrm{Ki}-67$ protein expressed in prokaryotes elicited high immunogenicity in mice.

The first MIB-1 mAbs against the recombinant fragment of $\mathrm{Ki}-67$ protein has been considered as the "gold standard" for immunochemical detection of this biomarker. Recent Ki-67 recognizing mAbs, SP6 and 309,were introduced as potential immunoreagents for routine clinical diagnostics.(15,31-33) According to the assessment international quality control shows that only two test systems based on the use of mAb MIB-1 (Dako) and 30-9 
(Ventana), has leading position in terms of laboratories use for assessing Ki-67 status and demonstrate the highest pass rate efficiency $95-100 \%$. The rabbit mAb SP6 turned out to be less popular for the detection of Ki-67, less than $10 \%$ use among laboratories. $(34,35)$

Determination of the Ki-67 protein expression level plays an important role in differentiating breast cancer into molecular subtypes. Increased expression of the Ki-67 protein is associated with poor prognosis of breast cancer. Ki-67-positive cases are characterized by aggressive growth and metastasis. A high level of expression of the $\mathrm{Ki}-67$ protein is associated with recurrence of breast cancer and overall low survival rate of patients. In normal breast tissue, the expression level of Ki-67 is very low.(36-38) Comparing the results of the expression of the biomarker $\mathrm{Ki}-67$ of the breast cancer using ICC and IHC methods, a significant correlation was obtained. The concordance of the results of ICC and IHC studies ranged from 81 to $92 \%$. $(6,7,8,9)$ Therefore, developing the monoclonal antibody for Ki-67 protein with higher of binding specificity has great importance. Immunoreagents as the main components of test systems are being improved to increase the sensitivity, reliability and efficiency of use.

In the present study, we developing novel mAbs with high specificity and binding activity to Ki-67 protein. Specific binding with target molecule is a well-known characteristic of antibody. The high affinity and binding activity of antibodies provide specificity and reduction of false negatives. High affinity and specificity of 4B8 hybridoma strain mAbs (4B8 mAbs) to recombinant Ki67 antigen was confirmed by indirect ELISA. The results Western blot showed that analytical sensitivity of the detection of Ki-67 antigen for 4B8 mAbs was below 100 ng. The application of newly generated anti-Ki67 mAbs in ICC provided showed the possibility of reliable detection of Ki-67 protein in cultured MCF-7 breast cancer cells. (39) The obtained 4B8 mAbs showed the identical level of nuclei staining as to the commercial anti-Ki-67 B56 mAbs that were used as a reference. B56 $\mathrm{mAbs}$ used as a positive control were obtained using a similar recombinant antigen Ki-67.(16) A large number of positively stained nuclei of cells and a bright intensity of their staining indicate a high level of proliferative activity of tumor cells in the studied preparations. Our results obtained from ELISA, Western blotting and ICC demonstrate that the newly developed mAbs are potentially useful as a immunodiagnostic tool for assessing the proliferative activity of breast tumor cells. The further research is focused on the use of obtained specific mAbs to evaluate the proliferative activity of breast tumor cells in FNA samples using ICC.

\section{Conclusion}

In this study, the synthesized the fragment of recombinant Ki-67 protein was used for obtaining of specific mAbs for assessing the proliferative activity of breast tumor cells. The production of specific mAbs, which makes it possible to reliably identify the Ki-67 biomarker protein, will make to use them for practical purposes - as a immunodiagnostic tool for the screening and early breast cancer diagnostics.

\section{Acknowledgements}

This work was funded by grant "Development of method for determining the Ki-67 biomarker for assessing the level of cell proliferation in malignant tumors" (AP05133251) from the Ministry of Education and Science of the Republic of Kazakhstan.

\section{Authors Contribution}

$\mathrm{AS}, \mathrm{KB}, \mathrm{ES}$ were involved in concepting and planning the research. All authors performed the data acquisition/ collection, calculated the experimental data and performed the analysis, drafted the manuscript and designed the figures, aided in interpreting the results. All authors took parts in giving critical revision of the manuscript.

\section{References}

1. Harbeck NC, Penault-Llorca FN, Cortes JA, Gnant MS, Houssami NF, Poortmans P, et al. Breast cancer. Nat Rev Dis Primers. 2019; 5: 66. doi: 10.1038/s41572-019-0111-2.

2. Savitri M, Bintoro UY, Sedana MP, Diansyah MN, Romadhon PZ Amrita PNA, et al. Circulating plasma miRNA-21 as a superior biomarker compared to CA 15-3: assessment in healthy age matched subjects and different stage of breast cancer patients. Indones Biomed J. 2020; 12: 157-64.

3. Meiliana A, Dewi NM, Wijaya A. Cancer immunotherapy: a review. Indones Biomed J. 2016; 8: 1-20.

4. International Agency for Research on Cancer [Internet]. Kazakhstan, Source: Globocan 2020 [updated Mar 2021; cited Mar 2021]. Available from: https:/gco.iarc.fr/today/data/factsheets/ populations/398-kazakhstan-fact-sheets.pdf.

5. Mansani FP, Bertucci MF, Montemór NP, Collaço LM, Pereira dos Santos JP. Evaluation of immunocytochemistry on the diagnosis of papillary mammary tumors by fine-needle aspiration biopsy. Mastology; 2019: 29: 90-6.

6. Garbar CB,Curé HP. Fine-needle aspiration cytology can play a role in neoadjuvantchemotherapy in operable breast cancer. Oncology. 2015; 92: 34-9.

7. Geethamala KN, Murthy VS, Vani BR, Rao MS, Thejaswini 
MU, Padmaja KP. Comparison of immunocytochemistry and immunohistochemistry on breast carcinoma: A boon or a bane? J Lab Physicians. 2017; 9: 5-10.

8. Pampa CT, Siddaraju NS, Kadambari DG, Kumar SD. Evaluation of estrogen and progesterone receptors and Her-2 expression with grading in the fine-needle aspirates of patients with breast carcinoma. J Cytol. 2018; 35: 223-8.

9. Osale CG, Mungania MS, Mutinda CK. Validation of fine needle aspiration cytology in the evaluation of human epidermal growth factor receptor-2 and hormonal receptor expressionpatterns in breast cancer patients. J Med Science Clin Research. 2019; 7: 107985.

10. Booth DC, Takagi MB, Sanchez-Pulido LA, Petfalski ED, Vargiu GR, Samejima K, et al. Ki-67 is a PP1-interacting protein that organises the mitotic chromosome periphery. Elife. 2014; 2014: e01641. doi: 10.7554/eLife.01641.001.

11. Scholzen TS, Gerdes JG. The Ki-67 protein: from the known and the unknown. J Cell Physiol. 2000; 182: 311-22.

12. Sun XV, Kaufman PD. Ki-67: more than a proliferation marker. Chromosoma. 2018; 127: 175-86.

13. Cuylen SV, Blaukopf CS, Politi AA, Müller-Reichert TN, Neumann B, Poser I, et al. Ki-67acts as a biological surfactant to disperse mitotic chromosomes. Nature. 2016; 535: 308-12.

14. Robertson SV, Stelhammar GS, Darai-Ramqvist EA, Rantalainen MF, Tobin NP, Bergh J, et al. Prognostic value of Ki67 analysed by cytology or histology in primary breast cancer. J Clin Pathol. 2018; 22: 1-8. doi:10.1136/jclinpath-2017-204976.

15. Ács BF, Kulka JB, Kovács KC, Teleki IG, Tőkés AF, Meczker Á, et al. Comparison of $5 \mathrm{Ki}-67$ antibodies regarding reproducibility and capacity to predict prognosis in breast cancer: does the antibody matter? Hum Pathol. 2017; 65: 31-40.

16. Maloy SS, Valley JB, Taylor RR. Genetic Analysis of Pathogenic Bacteria : A Laboratory Manual. Plainville: Cold Spring Harbor Laboratory Press; 1995.

17. Oi VL, Herzenberg LS. Immunoglobulin-producing hybrid cell lines. In: Mishell BA, Shiigi SS, editors. Selected Methods in Cellular Immunology. San Francisco: Freeman; 1980. p.363-5.

18. Coding JG. Antibody production by hybridoma. J Immunol Meth. 1980; 39: 285-308.

19. Bradford MM. A rapid and sensitive method for the quantitation of microgram quantities of protein utilizing the principle of proteindye binding. Anal Biochem. 1976; 72: 248-54.

20. Mahmood TS, Yang PC. Western blot: technique, theory, and trouble shooting. N Am J Med Sci. 2012; 4: 429-34.

21. Lestadi ID, Siregar NC, Wuyung PE. The correlation between TP53 expression and Ki-67 proliferation with Bartl malignancy degree of plasma cell neoplasm. Indones Biomed J. 2017; 9: 35-42.

22. Gerdes JS, Li LN, Schlueter CJ, Duchrow MA, Wohlenberg CB, Gerlach $\mathrm{C}$, et al. Immunobiochemical and molecular biologic characterization of the cell proliferation-associated nuclear antigen that is defined by monoclonal antibody Ki-67. Am J Pathol. 1991; 138: 867-73

23. Schmidt MF, Broll RN, Bruch HS, Finniss SX, Bögler OM, Duchrow M. Proliferation marker pKi-67 occurs in different isoforms with various cellular effects. J Cell Biochem. 2004; 91: 1280-92.
24. Key GS, Becker MK, Duchrow MJ, Schlüter CV,Gerdes JR. New Ki67-equivalent murine monoclonal antibodies (MIB 1-3) generated against bacterially expressed parts of the Ki-67cDNA containing three 62 base pair repetitive elements encoding for the Ki-67 epitope. Lab Invest. 1993; 68: 629-36.

25. Ross WS, Hall PA. Ki67: from antibody to molecule to understanding? Clin Mol Pathol. 1995; 48: M113-7.

26. Kubbutat MH, Key GG, Duchrow MA, Schlüter CS, Gerdes JN. Epitope analysis of antibodies recognising the cell proliferation associated nuclear antigen previously defined by the antibody Ki-67 (Ki-67 protein), J Clin Pathol. 1994; 47: 524-28.

27. Roche [Internet]. CONFIRM anti-Ki-67 (30-9) Rabbit Monoclonal Primary Antibody, Cat No. Cat. N. 790-4286 [cited Mar 2021]. Available from: https://pim-eservices. roche.com/eLD/api/downloads/fa95325e-7133-ea11-fa90005056a772fd? countryIsoCode $=$ us.

28. Abcam [Internet]. Recombinant Anti-Ki67 antibody [SP6] (ab16667) [cited Mar 2021]. Available from: https://www.abcam.com/ki67antibody-sp6-ab16667.html.

29. Chung BK, Lee DY. Computational codon optimization of synthetic gene for protein expression, BMC Syst Biol. 2012; 6: 134-9.

30. Hames BD. Gel Electrophoresis of Proteins: A Practical Approach. 3rd ed. Oxford: Oxford University Press; 1998.

31. Dowsett MA, Nielsen TK, A'Hern RN, Bartlett JS, Coombes RC. Assessment of Ki67 in breast cancer: recommendations from the International Ki67 in Breast Cancer working group. J Natl Cancer Inst. 2011; 103: 1656-64.

32. Viale GS, Hanlon AE, Walker EG, Harlow GK, Bai IO, Russo L, et al. Ki-67 (30-9) scoring and differentiation of luminal A- and luminal B-like breast cancer subtypes. Breast Cancer Res Treat. 2019; 178: 451-8.

33. Zabaglo LF, Salter JA, Anderson HN, Quinn ED, Hills MK, Detre S, et al. Comparative validation of the SP6 antibody to Ki67 in breast cancer. J Clin Pathol. 2010; 63: 800-4.

34. NordiQC [Internet]. Immunohistochemical Quality Control. [cited Mar 2021]. Available from: https://www.nordiqc.org/.

35. United Kingdom National External Quality Assessment Service (UK NEQAS). Breast HER2 ICC Module and Breast Steroid gormone receptor Module. London: UK NEQAS ICC ISH; 2021.

36. de Azambuja ED, Cardoso FA, de Castro GJr, Colozza MH, Durbecq $\mathrm{V}$, Sotiriou C, et al. Ki-67 as prognostic marker in early breast cancer: a meta-analysis of published studies involving 12,155 patients. Br J Cancer. 2007; 96: 1504-13.

37. Stuart-Harris RK, Caldas CB, Pinder SE, Pharoah PS. Proliferation markers and survival in early breast cancer: a systematic review and meta-analysis of 85 studies in 32,825 patients. Breast. 2008; 17 : 323-34.

38. Ragab HM, Samy N, Afify ME. Maksoud NA, Shaaban HM. Assessment of $\mathrm{Ki}-67$ as a potential biomarker in patients with breast cancer. J Genet Eng Biotechnol. 2018; 16: 479-84.

39. Prayogo AA, Wijaya AY, Hendrata WM, Looi SS, I'tishom R, HakimL, et al. Dedifferentiation of MCF-7 breast cancer continuous cell line, development of breast cancer stem cells (BCSCs) enriched culture and biomarker analysis. Indones Biomed J. 2020; 12: 11523. 